\title{
Determinants of Mothers Health Seeking Behaviour for Their Children in a Nigerian Teaching Hospital.
}

\author{
${ }^{1}$..Ajibade, B. L., ${ }^{2 .}$ Amoo, P. O., ${ }^{3 .}$ Adeleke, M. A., ${ }^{4 .}$ Oyadiran G.O, \\ ${ }^{5}$ Kolade O.A ${ }^{6}$ Olagunju R.O \\ Department of Nursing $1,2,4,5,6$ \\ Ladoke Akintola Teaching Hospital, Ogbomoso. ${ }^{3}$
}

\begin{abstract}
This is a descriptive study on determinant of health seeking behaviour of mothers for their children. The study examined the relationships between mother' age, occupation, support they received on their health seeking behaviour for their children as well as the type of health care institutions that they preferred to seek care for their children when sick.

One hundred and fifty nursing mothers were recruited from child welfare clinic of Urban Comprehensive Health Center of Ladoke Akintola University Teaching Hospital, Osogbo, Osun State, Nigeria. A semi structured questionnaire was used to elicit the respondents' opinion, while the analysis was done with the use of at a significant level of 0.05

This study reveals that majority of the mothers 54 (36\%) were between 31 and 35 years, while 62 (41.3\%) of the mothers brought their first born child. Most of the mothers preferred to take their children to government health institutions when sick, while only few of the mothers preferred mission hospital. The study also shows that mothers' occupation had no significant effect on when their perception as to when children should be taken to the hospital for treatment $(P=0.05)$. Income or finance is a strong determinant for the mothers to seek care for their children

In addition, age of the mother exerted a significant relationship on their perception as to when children should be taken for health care $(P=0.04)$. While type of support $(P=0.07)$ and level of support mothers received from their husbands $(P=0.27)$ had no significant influences on the type of health institution preferred by the mothers to seek care for their children.
\end{abstract}

Key words: Health seeking, behaviour, Determinant

\section{Introduction}

Globally, about 26,000 death of children under five years is recorded annually mainly from preventable diseases, more than half of the death occur in the developing countries ${ }^{9}$. Most of the cases have been associated with malnutrition and infections ${ }^{6}$. Appropriate health care seeking is of significant importance particular in areas with limited access to health services ${ }^{10,11}$. Therefore, it is important for families to respond timely to their children illnesses by seeking appropriate care whenever their child is sick ${ }^{12}$.

About 10.6 million children still die every year before reaching their fifth birthday, mostly among the low and middle income people. Most deaths among children of under- five years are still attributable to just a handful of conditions and are avoidable through existing interventions ${ }^{13,14}$. In Ethiopia, $75 \%$ of children who were taken for medical care suffers from preventable illnesses such as malaria, diarrhea, pneumonia, measles and micronutrient deficiency.

Diseases still remain the major causes of morbidity and mortality among young children, particularly in the developing countries of the world with about 13 million infant and children death in the developing countries ${ }^{15}$.

In recent years, attention of epidemiologists and social scientists have been devoted to studying health care-seeking behaviour associated with the two leading causes of child mortality, namely diarrhoeal illness and acute respiratory infection (ARI). However, the knowledge of how and when families in most developing countries seek treatment for their children regarding these prevalent illnesses remains seriously incomplete ${ }^{15,17}$. This study is considered important because good knowledge of factors surrounding parent's decision to seek health care for their children is particularly important. Belief of the parents and anticipation about outcome of therapy is a strong predictor to possible barrier in seeking treatment for their children or in premature termination of treatment. Equally, parent's socioeconomic status, age of the child, severity and level of dysfunction determine their health-seeking attitude ${ }^{18}$. Large number of children still die in the developing countries without reaching any health care facility regardless of various reported health seeking intervention ${ }^{1}$.

Multiple factor determines the child's access to health care by parents in Nigeria. Cultural practices, economic insecurity, political factors impede on equitable distribution of health care leading to health insecurity 
in Nigeria ${ }^{19}$. While in some other places accessibility to health care services, type and severity of disease, parent's gender, education determines pattern ${ }^{20}$. In addition, attitude of users to the health professionals, bad transportation system, self medication are other identified problems that affected health seeking for children ${ }^{20,21}$. Low economic income of parents influences their ability the health care seeking for their children and this becomes worsen as the child grows older ${ }^{23}$.

Persisting health crises in many Sub Sahara African countries results to high morbidity and mortality of under-five children ${ }^{24}$. Out of every 1000 births in Nigeria 75 die before the age of five ${ }^{25}$. Parents in all societies raise their children in a way that is generally compatible with the demands of their physical environment, socioeconomic conditions, demographic characteristics, and the belief system that has been ingrained in their society. Categorizations of health seeking pattern for children can be grouped as reoccurring determinants and placed into key spheres of influence like informal and formal infrastructure. A recent study conducted in the rural area of Bangladesh that $86 \%$ of women received health care from non-qualified health care providers ${ }^{26}$.

The implication of parents' belief about a particular disease is integral to the place and kind of care that will be sought when their child is sick especially in Nigeria. In some part of Nigeria, especially among the Yorubas in the western part diarrhea in children is not considered as a serious health disorder requiring hospital care but rather as a means through which the child gets rid of body impurities mostly during teething, crawling, while others believed it is as a result of consuming sweet things ${ }^{27}$. Mothers initially commence treatment for their sick children with the hope and belief that the child will soon get better, but when the condition deteriorates they are usually advised to seek the services of a qualified professional. Such treatment is mainly left over of adult drugs, or over the counter purchase, and it is mostly as a result of poor finances ${ }^{28}$. Therefore mothers with such belief may find it difficult to commence oral rehydration therapy at home for such children.

Timely intervention by taking children out for appropriate treatment is highly important rather than for parents to wait until when the child can neither eat or play or commenceself-medication ${ }^{12}$. The World Health Organization estimated seeking prompt and appropriate care could reduce child deaths due to acute respiratory infections by $20 \%{ }^{29}$.

The need to create and intensify community awareness about the significance of improving health careseeking from appropriate area is highly important. Traditional healers and other non professional health care provider need to be trained and incorporated into child health care ${ }^{30}$. In South Africa two main reasons why mothers choose to attend mainly clinics are because the cost is free and also most of the clinics are accessible to them just between one and five kilometers ${ }^{17}$.

This study adopted the health belief model proposed by a group of Social Psychologists in the United States Public Health Service in 1950s reviewed in 1974 and predicts that attitude of people towards heal care seeking is dependent on their belief about Perceived susceptibility (people's belief about cause and the likelihood of having such disease), perceived severity (how serious they understand such disease to be), perceived barrier (hindrances that can prevent them from taking action for example finance), Cues to action (the level of knowledge and information parents have about childhood illnesses help to determine possible action they will take), likelihood of action(confidence in the ability of parents helps them to take the prompt action in their children's illness) ${ }^{31}$.

\section{Statement of problem}

Almost half a million children are dying each year from easily preventable diseases despite the existing interventions. Even though care seeking interventions have the potential to substantially reduce child mortality, in developing countries large number of children die without ever reaching a health facility and due to delays in seeking care ${ }^{1}$.

In recent years, epidemiologists and social scientists have focused attention to studying the relationship between illness and health-seeking behavior. Evidence on health seeking-behavior has been documented in a few local studies ${ }^{2}$. Health-seeking behavior also includes consulting a physician during the prenatal (for mother's immunization against tetanus), natal (place of delivery and help at delivery) and postnatal (immunization of the child) period, especially when disease symptoms are apparent. Education of mother and father and their work status have strong effect on child survival in developing countries ${ }^{3}$.

Appropriate care-seeking is of particular importance in areas where access to health services is limited ${ }^{4}$. The impact of illnesses on growth may vary according to previous nutritional status of the child, the availability of food and access to health facilities. In Kenya studies show that higher prevalence of malnutrition is associated with higher morbidity rates other enabling factors such as proximity to the health facility and availability of funds were also important in determining health-seeking behavior ${ }^{5,2}$.

Education, alternative therapeutic care, tradition, gender disparity such as inability of wives to communicate freely with their husbands, matrimonial role neglect on the part of the husbands are factors responsible for non patronage of health care services ${ }^{6}$. Other enabling factors such as proximity to the health facility and availability of funds are also important determinants of health seeking behavior especially for 
children ${ }^{5}$. Lack of health insurance coverage especially among the low-income family also influences healthseeking behavior ${ }^{7}$. Delay in health seeking can also be associated with home/self treatment, use of traditional treatment, accessibility to health care services and money especially for children with acute fever and diarrhea ${ }^{8}$.

\section{Aim Of The Study.}

The aim of this study was to determine the factors that influence mothers' health-seeking behaviour for their children.

\section{Research Design:}

\section{Research Methodology}

This was a descriptive study that determined the health-seeking behavior of mothers toward the factors influencing their perception in bringing their chielren to the hospital for medical care at thes child welfare clinic, Comprehensive Health Centre of Ladoke Akintola University Teaching Hospital, Ita Akogun,Osogbo. This study was conducted for a period of four months(February - April,2013).

\section{Samlping Tecnnique And Sample Size Determination:}

One hundred and fifty mothers between 20 and 40 years old having children between zero and five years of age attending child welfare clinic at the Ladoke Akintola University Teaching Hospital Complex (LTH) Urban Comprehensive Health Centre, Akogun, Osogbo who gave consent to participate in this study were recruited through a purposive sampling after been due information about the study.

\section{Research Setting}

This study was conducted among nursing mothers whose children were between zero to five years of age attending child welfare clinic at Ladoke Akintola University Teaching Hospital Urban Comprehensive Health Centre, Ita-Akogun,Osogbo. This health institution is having many units which include,welfare clinic,geriatric unit,out-patient, etc.

\section{Instrument For Data Collection:}

A 24 item semi structure questionnaire was used to elicit responses from respondents. This was in three sections:

Section A: Demographic characteristics such as age of both mother and child, number of children, marital status, occupation, educational status.

Section B: Awareness of mothers about where to seek health care for their children and family support system available.

Section C: Factors that determine where mothers seek health care for their children. This was pretested before being administered.

\section{Method Of Data Analysis}

Data collected from this study was analyzed by using descriptive and inferential statistics.

SPSS version 19 window was used. Descriptive statistics method was used such as frequency tables and charts while inferential statistics was calculated by using student's $t$ test to analyze continuous variables and chi square was used to test the categorical variables. Level of significance was set at 0.05 .

\section{Findings}

Table 1: Age distribution of respondents

\begin{tabular}{|l|c|c|}
\hline Age in year & Frequency & Percentage \\
\hline $20-25$ & 42 & 28 \\
\hline $26-30$ & 10 & 6.7 \\
\hline $31-35$ & 54 & 36 \\
\hline $36-40$ & 44 & 29.3 \\
\hline Total & 150 & 100 \\
\hline
\end{tabular}

A total of 150 mothers that brought their children to child welfare clinic were used as the respondents in this study. The table above shows that 54 (36\%) of the respondents are between 31 and 35 years, $44(29.3 \%)$ are between 36 and 40 years old, $42(28 \%)$ are between 20 and 25 years old while $10(6.7 \%)$ of the respondents are between 26 and 30 years of age. 
Table 2: Position of the child in the family

\begin{tabular}{|l|c|c|}
\hline Position of the child in the family & Frequency & Percentage \\
\hline First born & 62 & 41.3 \\
\hline Second born & 59 & 39.3 \\
\hline Third born & 29 & 19.3 \\
\hline Total & 150 & 100 \\
\hline
\end{tabular}

Table 2 shows that most of the mothers $62(41.3 \%)$ brought their first born child to the clinic, $59(39.3 \%)$ of the mothers brought their second born while 29 (19.3\%) of the mothers brought their third born child to the clinic. This is an indicative that majority of the respondents were having their first born child.

Table 3: Knowledge of respondents on what is health seeking behaviour is

\begin{tabular}{|l|c|c|}
\hline $\begin{array}{l}\text { What people know as health seeking } \\
\text { pattern }\end{array}$ & Frequency & Percentage \\
\hline $\begin{array}{l}\text { The way people seek health care } \\
\text { when the need arises }\end{array}$ & 8 & 5.3 \\
\hline Health care available & 33 & 22.0 \\
\hline Attitude towards seeking health & 109 & 72.7 \\
\hline Total & 150 & 100 \\
\hline
\end{tabular}

The respondents' understanding of health care seeking for childhood diseases varies, 109 (72.7\%) of the respondents perceived that health care seeking pattern is the sum of attitude of individuals toward about looking for solution to particular health disorder in a given place believed to be appropriate, 33 (22\%) understand that health-care seeking pattern as health care services available to them when there is a particular health challenge, while 8 (5.3\%) believed that health care seeking pattern is the way people seek for health care services when the need arises. Responses of the respondents indicate that there is still a poor understanding of what health-care seeking pattern means to the majority of the respondents.

Table 4: When mothers perceived that their children needed to be taken for health care

\begin{tabular}{|l|c|c|}
\hline $\begin{array}{c}\text { When mothers take their children for } \\
\text { health care }\end{array}$ & Frequency & Percentage \\
\hline Stop playing & 39 & 26 \\
\hline There is sudden change in health & 99 & 66 \\
\hline Condition deteriorating & 12 & 8 \\
\hline Total & 150 & 100 \\
\hline
\end{tabular}

Table 4 shows that the knowledge of the mothers on when they consider that their children needed to be taken for health-care. Their understanding of when this is necessary also varies $39(26 \%)$ of the respondents believed that their children needed to be taken for health-care when the child stop playing, 99 (66\%) reported that their children should be taken for health-care whenever they noticed or observed a change in child's health condition. While $12(8 \%)$ reported that their children needed to be taken for health-care when they noticed that the condition of the child is deteriorating. Although majority of the mothers reported that they used to take their children out for care when they noticed a sudden change in their condition, there is the need to intensify health education of the mothers as regarding how to observe for changes in their child condition as well as taking prompt action to take them for health care.

Table 5: Health institution preferred by mothers

\begin{tabular}{|l|c|c|}
\hline Proffered hospital & Frequency & Percentage \\
\hline Private hospital & 16 & 10.7 \\
\hline Government hospital & 132 & 88 \\
\hline Mission hospital & 2 & 1.3 \\
\hline Total & 150 & 100 \\
\hline
\end{tabular}

This table shows mothers preference of health care facilities to seek care for their children when sick. Health care facilities in Osogbo can be classified into three categories namely, government hospitals comprising of University teaching hospital, state government hospital and local government health centres. Private hospital comprises of all health institutions owned by individuals while the mission hospital is the hospital owned by religious organization. This study shows that $16(10.7 \%)$ of the respondents preferred private hospitals or clinics, $132(88 \%)$ preferred government hospitals while $2(1.3 \%)$ preferred the mission hospital. 
Table 6: Level of support received by mothers from their spouse for their child health care

\begin{tabular}{|l|c|c|}
\hline Level of support & Frequency & Percentage \\
\hline Highly Supportive & 107 & 71.3 \\
\hline Not supportive & 41 & 27.3 \\
\hline Little support & 2 & 1.3 \\
\hline Total & 150 & 100 \\
\hline
\end{tabular}

The table above shows the level of support that the mothers received towards taking their children for health care. Majority or 107 (71.3\%) of the mothers were highly supported in seeking care for their children, 41 $(27.3 \%)$ received no support while $2(1.3 \%)$ recived little support in the care of their children when sick.

Table 7: Kinds of support enjoyed by mothers

\begin{tabular}{|l|c|c|}
\hline Type of support & Frequency & Percentage \\
\hline Financial & 91 & 60.7 \\
\hline Psychological & 24 & 16.0 \\
\hline Prayer & 30 & 20 \\
\hline Others & 5 & 3.3 \\
\hline Total & 150 & 100 \\
\hline
\end{tabular}

Table 7 above shows the type of support that the mothers received for the care of their children when sick, $91(60.7 \%)$ of the mothers received financial support, 24 (16\%) were given psychological support supported, $30(20 \%)$ were prayed for while $5(3.3 \%)$ received other forms of support.

Table 8: Age of mothers as a determinant for health seeking behaviour

\begin{tabular}{|l|c|c|}
\hline Mothers' age as a determinant & Frequency & Percentage \\
\hline Determinant & 108 & 72 \\
\hline Non determinant & 40 & 26.7 \\
\hline No idea & 2 & 1.3 \\
\hline Total & 150 & 100 \\
\hline
\end{tabular}

Majority or $108(72 \%)$ of the respondents believed that age of the mothers is a strong determinant on when they take their sick children for health care, $40(26.7 \%)$ of the mothers believed that mothers' age has no influence on their decision to take their sick children for health care services, while $2(1.3 \%)$ of the mothers had no idea of the influence of age on when the mothers take their children for health care.

Table 9: Respondents' opinion on the Influence of income as determinant for health seeking behavior of mothers

\begin{tabular}{|l|c|c|}
\hline Opinion & Frequency & Percentage \\
\hline Had influence & 136 & 90.7 \\
\hline Had no influence & 14 & 9.3 \\
\hline Total & 150 & 100 \\
\hline
\end{tabular}

The table above shows that most of the mothers or $136(90.7 \%)$ believed that mothers' income is a strong determinant of their health seeking pattern, while $14(9.3 \%)$ of the mothers stated that income had no influence on the health seeking pattern of the mothers for their children when sick.

Table 10 Influence of mother occupation on when and where to seek health care for children

\begin{tabular}{|l|c|c|}
\hline Mothers' opinion & Frequency & Percentage \\
\hline Have an influence & 138 & 92 \\
\hline Have no influence & 12 & 8 \\
\hline Total & 150 & 100 \\
\hline
\end{tabular}

This table shows that $138(92 \%)$ of the of the respondents agreed that mothers' occupation determines when and where their child will be taken to in order to receive health care when sick. While $12(8 \%)$ claimed that mothers' occupation did not impart when and where their children will be taken to when sick.

Table 11 Opinion of mothers on the influence support towards health care seeking behavior

\begin{tabular}{|l|c|c|}
\hline Mothers' opinion & Frequency & Percentage \\
\hline Have a strong influence & 95 & 63.3 \\
\hline Have no influence & 55 & 36.7 \\
\hline Total & 150 & 100 \\
\hline
\end{tabular}


The table above shows that majority of the mothers 95 (63.3) believed that support given to the mothers significantly influences their health seeking pattern for their sick children, while 55 (36.7\%) did not believe that the support received influences their health seeking pattern.

Table 12: Influence of mother's age on mother's belief on when to take their children for health care

\begin{tabular}{|l|c|c|c|}
\hline \multirow{2}{*}{ Age of mother } & \multicolumn{2}{|l|}{ Mother's belief on when to take children for health care } \\
\cline { 2 - 4 } & Stop playing & $\begin{array}{l}\text { There is sudden change in } \\
\text { health }\end{array}$ & Condition worsen \\
$X^{2}=8.3$ \\
\hline $20-25$ & 23 & 19 & 0 \\
\hline $26-30$ & 0 & 0 & 10 \\
\hline $31-35$ & 12 & 40 & 2 \\
\hline $36-40$ & 4 & 40 & 0 \\
\hline Total & 39 & 99 & 12 \\
\hline
\end{tabular}

The table above indicates that age of the mothers is a very strong determinant on their understanding of when they need to take their children for the health care when sick. The table shows that older mothers are more experienced on identification of when their children needed to be taken to for care. This table shows that 40 of the respondents between the ages of 35- 40 years and 36-40 years respectively understand that children needed to be taken to be taken for health care as against 10 between the age of 26-30 that said when the condition of the child deteriorate and 23 between the ages of 20-25 years that reported that when the child suddenly stop playing.

Table 13: Influence of respondents' occupation on their belief towards taking their children for health care

\begin{tabular}{|c|c|c|c|c|}
\hline \multirow[t]{2}{*}{ Occupation of mother } & \multicolumn{3}{|c|}{ Mother's belief on when to take children for health care } & \\
\hline & Stop playing & $\begin{array}{l}\text { There is sudden change } \\
\text { in health }\end{array}$ & Condition & \multirow{5}{*}{$\begin{array}{l}X^{2}=2.5 \\
d f=6 \\
P=0.05\end{array}$} \\
\hline Teaching & 12 & 35 & 1 & \\
\hline Nursing & 19 & 34 & 0 & \\
\hline Civil servant & 7 & 13 & 1 & \\
\hline Total & 39 & 99 & 12 & \\
\hline
\end{tabular}

Although the above table shows that some of the respondents are nurses, this does not influence the respondents' perception of when to take their children for health care when they noticed that they are sick. The table above shows that 35 of the respondents that are teachers and 34 of the respondents that are nurses claimed that their children will be taken to the health care centre for care whenever they noticed a sudden change in their child's health, while 19 nurses, 12 teachers and 7 civil servants claimed that they will take their children for care when the child stop playing as compared with 1 respondent each who are teacher and civil servant respectively and none of the nurses that said they will take their children for care when the condition deteriorates.

Table 14: Influence of kind of support on the health institutions mothers preferred to seek health care for

\begin{tabular}{|l|c|c|c|c|}
\hline \multirow{2}{*}{ Kind of support enjoy } & \multicolumn{2}{|c|}{ Health institution preferred } & \multirow{3}{*}{ Statistical value } \\
\cline { 2 - 4 } & $\begin{array}{l}\text { Private } \\
\text { hospital }\end{array}$ & Government hospital & Mission hospital & \multirow{2}{*}{$\mathrm{X}^{2}=11.8$} \\
\hline Financial & 5 & 84 & 2 & \multirow{2}{*}{$\mathrm{df}=6$} \\
\hline Psychological & 0 & 24 & 0 & \multirow{2}{*}{$\mathrm{P}=0.001$} \\
\hline Prayer & 11 & 19 & 0 & \\
\hline Others & 0 & 5 & 2 & \\
\hline Total & 16 & 132 & & \\
\hline
\end{tabular}

This table 14 shows that the kind of support mothers received is a very strong determinant to the type of health-care institution where they seek health care for their children, 84 of the respondents that received financial assistance preferred government hospital as compared with only 2 that preferred mission hospital and 5 of those receiving financial support preferred private hospital. However, only 11 of all other respondents preferred private hospital and none preferred mission hospital. 


\section{Discussion}

Understanding health seeking behaviour, health promotion programs worldwide have long been premised on the idea that providing knowledge about causes of ill health and choices available will go a long way towards promoting a change in individual behaviour, towards more beneficial health seeking behaviour.

However, there is growing recognition, in both the developed and developing countries, that providing education and knowledge at the individual level is not sufficient in itself to promote a change in behavior.

Health-seeking behaviour also includes consulting a physician during the prenatal (for mother's immunization against tetanus), natal (place of delivery and help at delivery) and postnatal (immunization of the child) period, especially when disease symptoms are apparent. Education of mother and father and their work status have strong effect on child survival in developing countries. Educated women tend to provide better healthcare, hygiene and are more likely to seek help when a child is ill ${ }^{5}$. Occupation of mothers is a determinant of their economic status, this study shows that mothers' occupation had no significant relationship on when they believed children should be taken to the hospital for treatment $(\mathrm{P}=0.05)$, as well as on the type of health institution the mothers preferred to receive care for their children $(\mathrm{P}=0.66)$. However majority of the mothers $135(90.7 \%)$ reported that finance is a strong determinant for them towards seeking care for their children. While previous study have shown that poverty is a serious constraint on a family's choices about how to treat children's illnesses ${ }^{15}$.Parents' socioeconomic status, age of the child, severity of dysfunction determine their health seeking attitude ${ }^{18}$.

This study shows that age of the mother exerted a significant relationship on when they believed their children should be taken for health care $(\mathrm{P}=0.04)$. There were marked differences in the behaviour patterns when mothers were grouped under forty and above forty ${ }^{5}$. The concern of parents especially mothers when their children is sick is highly alarming. However, the behaviours of the mothers towards seeking care for their children vary. This variance can be traced down to certain factors some of which are beyond the control of the mothers. Some of these include income, culture, family support system, personality and women independence to take decision. This study also shows that type of support $(\mathrm{P}=0.07)$ and level of support mothers received from their husbands $(\mathrm{P}=0.27)$, influences the type of health institution where they sought health care for their children. While mothers' age had no significant difference on effectiveness of the support they received. In Kenya, studies show that higher prevalence of malnutrition is associated with higher morbidity rates. Other enabling factors such as proximity to the health facility and availability of funds were also important in determining health-seeking behavior ${ }^{5,2}$. Large numbers of children still die in the developing countries without reaching any health care facility regardless of various reported health seeking intervention ${ }^{1}$.

This could be due to differences in access to health facilities, educational backgrounds, cultural factors and socio economic status.

\section{Conclusion}

This study concludes that mothers' occupation conferred a no significant relationship on when they believed children should be taken to the hospital for treatment $(\mathrm{P}=0.05)$, also occupation and level of support mothers received is not a determinant of the health institution they preferred to receive care for their children $(\mathrm{P}$ $=0.27)$ and $(p=0.07)$ respectively. Age of the mother was another strong determinant of when their children were taken for health care $(p=0.04)$. In addition level of support that the mothers received and the type of support they received significantly influenced their choice of health care institution where their children received treatment $(\mathrm{p}=0.004$ and $\mathrm{p}=0.001)$.

This study shows that:

\section{Recomendation}

$>$ There is the need for nurses to intensify health education given to mothers concerning seeking care for their children.

$>$ There is also the need for active involvement of the spouses and other family members to provide good support in the area of finance for the mothers to seek care for their children when sick.

$>$ Young mothers need to be educated at the child welfare clinics on the importance of early detection of illnesses in their children and the need to seek prompt and adequate care.

\section{Acknowledgement}

We want to express our profound gratitude to the authorities of Ladoke Akintola University Teaching Hospital, Akogun Comprehensive Health centre Ita-Akogun, Osogbo and Osun State Health Management Board hospital, Asubiaro for the permission and support granted during the course of this study. 


\section{References}

[1]. Terra de .S, Peterson .K.E, Andrade .F.M, Gardner. J, Ascherio. A Circumstances of post-neonatal death in Ceara, Northeast Brazil. Mothers health care-seeking behaviors during infants fatal illness.Social Science and Medicine, 2000;51:1675-1693.

[2]. Kenya Demographic Health Survey. Central Bureau of Statistics, Ministry of Health, Kenya Medical Research Institute, National Council for Population and Development. Centre for Mariam C, Ronald J, Waldman (2000). The Evolution of Child Health programs in developing Countries: From Targeting Diseases to Targeting people, Genebra, Bulletin of WHO, 2000; 78 (10) 3

[3]. Caldwell, J.C. "Education as a factor in mortality decline: An examination of Nigerian data" Population Studies. 1979;33(3): 395414.

[4]. Mbagaya.G.M,OdhiamboM.O, ${ }^{2}$ andOniang'o.R.K (2005) Mother's health seeking behaviour during child illness in a rural western Kenya community. African Health Science. 2005;5(4): 322-327.)

[5]. Odubanjo.M.O, Olumide.Y.M.Reducing child mortality in Nigeria : the way forward workshop summary. 2009

[6]. Allison .T.E Factors affecting access to health care for rural Arizona minority. Master's Thesis submitted to university of Arizona. 2005

[7]. Tsion.A, Tefera .B, Ayalew .T, Amare. D Mothers' health care seeking behavior for childhood illnesses in Derra District, Northshoa Zone, Oromia. .Ethiop J Health Science. 2008; 18 (3): 87-94

[8]. Black R E, Morris S S, Bryce J. Where and why are 10 million children dying each year? The Lancet.2003; $361: 2226-2234$.

[9]. Mariam C, Ronald J, Waldman (2000). The Evolution of Child Health programs in developing Countries: From Targeting Diseases to Targeting people, Genebra, Bulletin of WHO. 2000; 78 (10); 3

[10]. Aguilar A., Alvarado R., Cordero D. Kelly P, Zamora A \& Salgado R; Mortality Survey in Bolivia, the Final Report. Investigating and Identifying the Causes of Death for Children Under Five. BASICS, Virginia, 1998.

[11]. World Health Organization (WHO). African Region Ethiopia Integrated Management of Childhood Illness. WHO. 2001

[12]. World Health Organization (WHO). World Health Report, Geneva, Switzerland. 2004

[13]. World Health Organization (WHO). Child Survival a Strategy for the African Region fifty-sixth session Addis Ababa, Ethiopia, 28 Aug-1 September 2006

[14]. Assefa. T,Belachew. T andTegegn.A.Mothers' health care seeking behaviour for childhood illnesses in Derra District, NorthshorezoneOromia Regional State.Ethiopia Ethiop J Health Science. 2008; 18(3): 87-94).

[15]. GoldmanandHewell. Health-seeking behaviour for child illness in GuatemalaNoreen Goldman1 and Patrick Heuveline.Tropical Medicine and International Health.2000; 5 (2):145-155

[16]. Promtussananon.S, IPeltzer.K. Health seeking behaviour for child illnesses among rural mothers in South Africa: A pilot study. Health SA Gesondheid. 2003; 8(2); 3-13

[17]. Nock M.K and Kazdin,A.E. Parent's expectancies for child therapy: assessment and relation to participation in treatment. Journal of child and familystudies. 2001; 10:155-180

[18]. Odebiyi A.I and Ekong,S.C .Mothers' concept of measles and attitudes towards the measles vaccine in Ile-Ife.Nigeria Journal of Epidemiology and Community Health. 1982, 36: 209-213

[19]. Ahmed SM. Differing health and health seeking behaviour: ethnic minorities of the Chittagong hill tracts, Bangladesh. Asia Pacific Journal of Public Health.2001;13:100-108

[20]. Yadav S.P, Sharma RC and Joshi V. Study of social determinants of malaria in desert parts of Rajasthan.India.Journal of VectorBorne Disease.2005;42(4):141-146.

[21]. Nyamongo I.K. Health care switching behaviour of malaria patients in a Kenyan rural community. Social Science Medicine.2002;54: 377-386

[22]. Case.AandPaxson. CChildren's Health and Social Mobility. The future of children. 2006;16 (2): 151-173

[23]. United Nation International Children Emergency Fund (UNICEF). The State of World's Children, UNICEF, New York. 2000

[24]. National Population Commission. Nigeria demographic and Health Survey. 2008phic and

[25]. Rahman SA. Utilization of Primary Health Care Services in Rural Bangladesh: the population and provider perspectives Unpublished PhD Thesis submitted to London School of Hygiene and Tropical Medicine, University of London. 2000

[26]. Jinadu, M.K.; Olusi, S.O.; Agun, J.I. and A.K. Fabiyi. Childhood diarrhea in Journal of Diarrhea Diseases Research. 1991;9(4): 323-327.

[27]. Yadav.S.P.A study of treatment seeking behaviour for malaria and its management in febrile children in rural part of desert, Rajasthan, India.Journal of Vector Borne Disease. 2010; 47: 235-242

[28]. Victora C, Jennifer B, Olivier F, Roeland M. Reducing deaths from diarrhoea through oral rehydration therapy.Bulletin of WHO. 2000;1(78): 10

[29]. Ahmed.S, Sobhan.F, Islam.A, and Barkat-e-Khuda. Neonatal morbidity and care-seeking behaviour in rural Bangladesh.Journal of Tropical Pediatrics.2001;47. 98-105

[30]. Glanz, K., Rimer, B.K. \& Lewis, F.M. Health Behavior and Health Education. Theory, Research and Practice. San Fransisco: Wiley and Sons. 2002. 